\title{
MODEL EOQ DENGAN PRODUK BERKUALITAS TIDAK SEMPURNA UNTUK KASUS PESANAN YANG MENINGKAT DENGAN LAMA SIKLUS YANG SAMA
}

\author{
Oktora Yogi Sari \\ Universitas Widyatama \\ Jalan Cikutra 204 A Bandung \\ oktora.yogisari@widyatama.ac.id
}

\begin{abstract}
Abstrak
EOQ merupakan model pengendalian inventori yang konsepnya digunakan oleh banyak industri. Namun konsep EOQ memiliki berbagai kelemahan diantaranya berbagai asumsi yang tidak realistis sehingga banyak peneliti yang mengembangkan model EOQ yang disesuaikan dengan realita yang ada. Makalah ini disusun berdasarkan hipotesis dimana kondisi inventori terus bertambah sesuai dengan permintaan konsumen dan dalam inventori tersebut terdapat sejumlah produk yang tidak dalam keadaan sempurna (cacat). Seluruh produk yang diterima harus melalui proses pemeriksaan terlebih dahulu. Setelah melalui proses pemeriksaan, produk-produk yang cacat dapat diperbaiki untuk kemudian dijual dengan harga yang lebih rendah. Makalah ini membahas kasus khusus dari model yang dikembangkan oleh Salameh dan Jaber (2000). Untuk menggambarkan situasi inventori tersebut, makalah ini mengembangkan model matematika dan contoh numerik yang sesuai
\end{abstract}

Kata kunci : EOQ, model, inventori, produk cacat

\begin{abstract}
EOQ is an inventory control modelling that is widely used by industries. However, the concept itself has many weakness, such as unrealistic assumptions. Therefore, many researchers today have developed the more realistic EOQ models, which are able to describe the factual condition dealt by indsutries. This paper is written by the hypothesis, in which the amount of inventory is growing corresponds to the customers demand, and there are imperfect products. All products need to be checked, and the imperfect products are repaired to be sold at lower price. This paper discuss a special case derived from model by
\end{abstract}

Salameh and Jaber (2000). To describe the inventory situation, this paper developed a mathematical model and a corresponding numerical exampel.

Keywords : EOQ, model, inventory, imperfect items,

\section{Pendahuluan}

Fungsi perencanaan dan pengendalian inventori terdiri atas dua bagian, yaitu perencanaan inventori dan pengendalian inventori. Perencanaan inventori menentukan kebutuhan material seperti komponen, suku cadang, bahan baku, pasokan, dan lain-lain. Pengendalian inventori berkenaan dengan tingkat inventori yang tepat, titik pemesanan kembali (reorder point), persediaan pengaman, dan lain-lain.

EOQ merupakan pionir bagi model pengendalian inventori yang diperkenalkan sejak awal abad ini dan konsepnya digunakan oleh banyak industri. Namun konsep EOQ memiliki berbagai kelemahan dari berbagai sudut pandang. Antara lain beberapa asumsi yang tidak realistis. Hal ini mendorong banyak peneliti mengembangkan teori-teori baru mengenai pengendalian inventori yang disesuaikan dengan realita yang ada. Diantaranya adalah sebagai berikut.

Tersine (1988) mengemukakan empat kondisi inventori yang berhubungan dengan jumlah permintaaan dan lead time (waktu ancang-ancang), yaitu (1) kondisi dimana permintaan dan lead time bersifat konstan; (2) kondisi dimana permintaan berubah-ubah dan lead time konstan; (3) kondisi dimana permintaan konstan dan lead time berubahubah; sedangkan kondisi (4) adalah kondisi dimana permintaan dan lead time berubah-ubah. Asumsi inventori pada keempat kondisi permintaan dan lead time ini adalah tidak melalui proses pemeriksaan dan 
seluruh inventori berada dalam kondisi sempurna (tidak cacat).

Yanasse (1990) mengkaji tentang antisipasi kenaikan harga dan dampak yang ditimbulkan terhadap EOQ yang terjadi. Salameh dan Jaber (2000) mengembangkan model EPQ dengan asumsi bahwa setiap lot pesanan akan melalui proses pemeriksaan dan ada sejumlah produk rusak pada setiap lot pesanan tersebut. Produk-produk yang rusak dalam setiap lot pesanan ini dapat diperbaiki untuk kemudian dijual pada akhir periode dengan harga yang lebih rendah daripada harga produk yang tidak rusak.

Wen-kai dan Hong-Fwu mengembangkan model Salameh dan Jaber (2000) dengan mengkaji model inventori untuk produk cacat pada saat ada potongan harga dimana produk-produk cacat tersebut melalui proses pemeriksaan $100 \%$ dan kemudian dapat dijual sekaligus ketika proses pemeriksaan berakhir. Model yang dikembangkan oleh Wen-Kai dan Hong-Fwu (2009) sesuai dengan kenyataan bahwa program potongan harga dapat diberikan kapanpun. Terdapat tiga kondisi potongan harga, yaitu bagaimana jika potongan harga diberikan ketika proses pemeriksaan berakhir, bagaimana jika potongan harga diberikan ketika proses pemeriksaan belum dimulai, dan bagaimana jika potongan harga diberikan ketika proses pemeriksaan sudah hampir selesai.

Menilai keempat referensi yang ada, maka model yang akan dikembangkan oleh penulis pada makalah ini adalah model yang mengkaji bagaimana jika permintaan bersifat linier. Hal ini didasarkan pada realita bahwa pada waktu datangnya hari-hari besar, produsen atau pedagang besar cenderung memiliki inventori yang cenderung meningkat sesuai dengan meningkatnya permintaan konsumen.

\section{KAJIAN LITERATUR}

Secara sederhana, model yang dikembangkan oleh Salameh dan Jaber dapat dilihat pada gambar 1 berikut. $y$ merupakan tingkat permintaan, $T$ adalah lama siklus, $p y$ adalah sejumlah produk cacat yang diambil dari inventori, dan $t$ merupakan waktu yang digunakan untuk sejumlah $y$ unit yang dipesan untuk setiap siklus.

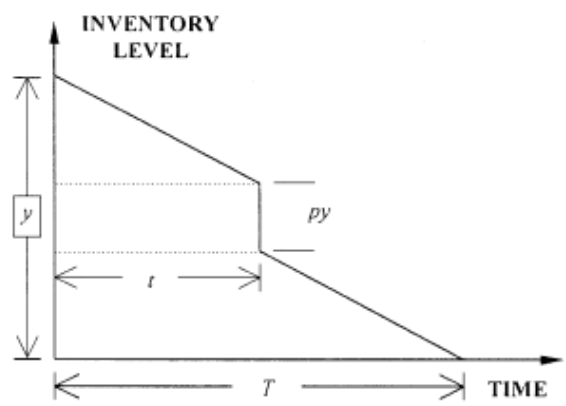

Gambar 1. Model inventori Salameh dan Jaber (Salameh \& Jaber, 2000)

Untuk setiap tingkat kerusakan $p$ pada setiap lot pemesanan $y$, maka total ongkos $T C(y)$, yang terdiri atas ongkos pengadaan, ongkos pemeriksaan, dan ongkos simpan adalah:

$$
T C(y)=(a+c y)+w y+c b\left[\frac{y(1-p) T}{2}+\frac{p y^{2}}{s}\right]
$$

$p$ merupakan variabel acak dengan fungsi kepadatan yang diketahui, $f(p)$, dengan demikian ekspektasi total profit per unit, $\operatorname{ETPU}(y)$, dapat dihitung dengan persamaan sebagai berikut:

$$
\begin{aligned}
\operatorname{ETPU}(y)= & D\left(s-v+\frac{h y}{x}\right)+D\left(v-\frac{h y}{x}-c-d-\frac{K}{y}\right) \\
& \times E\left[\frac{1}{1-p}\right]-\frac{h y(1-E[p])}{2}
\end{aligned}
$$

Optimalitas $y$ dapat diperoleh dengan menghitung turunan kedua dari persamaan $\operatorname{ETPU}(y)$, dan diperoleh:

$$
y^{*}=\sqrt{\frac{2 K D E\left[\frac{1}{1-p}\right]}{h\left[1-E[p]-\frac{D\left(1-E\left[\frac{1}{1-p}\right]\right)}{x}\right]}}
$$

\section{ANALiSis dan PeranCangan}

Model ini mencoba mengemukakan jika permintaan besifat linier dan barang yang dipesan diterima sekaligus dengan harga pembelian $c$ per unit 
dan ongkos pemesanan $K$, dan diasumsikan bahwa setiap lot yang diterima mengandung sejumlah $p$ produk cacat dengan fungsi kepadatan $f(p)$. Setiap lot yang diterima akan melalui proses pemeriksaan $100 \%$ dengan kecepatan $x$ unit per satuan waktu. Produk cacat dapat dijual pada akhir siklus dengan harga $v$ per unit sedangkan produk yang tidak cacat dijual dengan harga $s$ per unit.

Model ini mencoba mengemukakan jika permintaan besifat linier dan barang yang dipesan diterima sekaligus dengan harga pembelian $c$ per unit dan ongkos pemesanan $K$, dan diasumsikan bahwa setiap lot yang diterima mengandung sejumlah $p$ produk cacat dengan fungsi kepadatan $f(p)$. Setiap lot yang diterima akan melalui proses pemeriksaan $100 \%$ dengan kecepatan $x$ unit per satuan waktu. Produk cacat dapat dijual pada akhir siklus dengan harga $v$ per unit sedangkan produk yang tidak cacat dijual dengan harga $s$ per unit.

Jika $N(y, p)$ adalah sejumlah produk tidak cacat pada setiap lot pesanan, maka ukuran lot dikurangi dengan sejumlah produk cacat direpresentasikan sebagai berikut:

$N(Q, p)=y-p y=(1-p) y$

Agar tidak terjadi kekurangan, maka diasumsikan bahwa persediaan produk tidak cacat $N(Q, p)$ adalah sama dengan tingkat permintaan selama waktu pemeriksaan $t$, yaitu:

$N(y, p) \geq D t$

Dimana $D$ adalah jumlah permintaan per tahun. Dengan mensubstitusikan persamaan (1) pada persamaan (2), dan menggantikan $t$ dengan $y / x$, maka nilai $p$ dibatasi oleh:

$p \leq 1-\frac{\lambda Q}{s} p$

Notasi yang digunakan pada makalah ini adalah sebagai berikut:

Q : : Tingkat permintaan / pemesanan

$\Delta \mathrm{Q}_{\mathrm{n}} \quad: \quad$ Perubahan tingkat pemesanan

$\mathrm{T}$ : Lama siklus

$\mathrm{p}$ : Persentase produk cacat

a : Ongkos pemesanan

c : Ongkos pembelian w : Ongkos pemeriksaan

h : Ongkos simpan

v : Harga jual produk cacat

$\mathrm{x} \quad$ : Harga jual produk tidak cacat

M : Nilai ekspektasi dari $(1-\mathrm{p})$

$\mathrm{s}$ : Tingkat pemeriksaan produk cacat

Asumsi-asumsi pada makalah ini adalah sebagai berikut:

a. Permintaan mengalami peningkatan dalam $n$ siklus tertentu.

b. Persentase kerusakan berubah-ubah sesuai dengan pertambahan tingkat pemesanan

c. Lama setiap siklus sama.

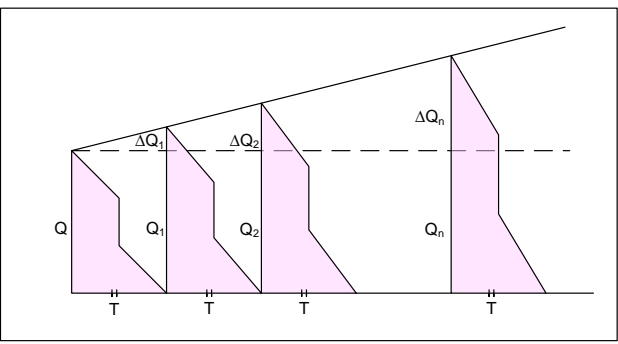

Gambar 2. Perilaku inventori dengan jumlah lot pesanan yang meningkat selama $n$ siklus

Inisial $y=Q$

Inisial $\Delta y=\Delta Q$

Diambil kasus $\Delta Q=p \cdot Q$

Persamaan (1a) memiliki arti bahwa kenaikan jumlah lot pesanan $(\Delta Q n)$ adalah total persentase kerusakan barang dikali dengan jumlah lot pesanan yang diterima pada silus sebelumnya ( $p . Q n)$

Jumlah lot pesanan pada siklus kedua adalah jumlah lot $(Q)$ yang diterima pada pada siklus sebelumnya ditambah dengan kenaikan jumlah lot pesanan pada siklus yang bersangkutan $\left(\Delta Q_{n}\right)$, yaitu:

$$
\begin{aligned}
& Q_{1}=Q+\Delta Q \\
& Q_{2}=Q_{1}+\Delta Q_{2} \\
& : \\
& : \\
& Q_{n}=Q+\Delta Q_{n}
\end{aligned}
$$

Dengan persentase kerusakan $0 \leq p \leq 1$ 


\subsection{Jumlah Lot Pesanan Pada Siklus Awal (Q)}

$Q$ merupakan jumlah lot pesanan awal yang dijadikan acuan dimana pertambahan jumlah lot pesanan pada siklus berikutnya setara dengan persentase kerusakan barang $(p)$ yang diterima pada $Q$ $(p \times Q)$.

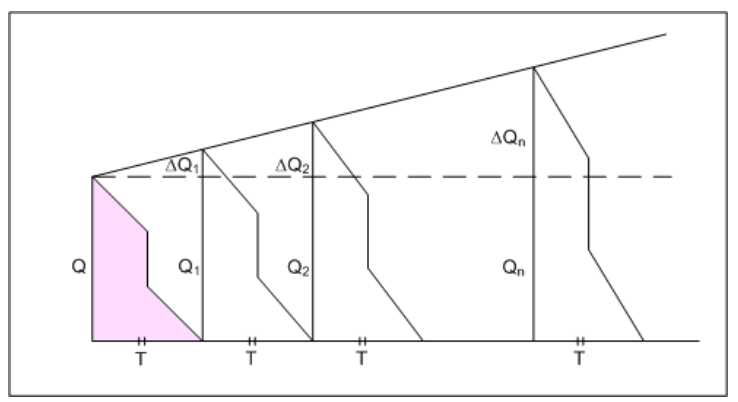

Gambar 3. Jumlah lot pesanan pada siklus awal $(Q)$

$Q$ merupakan jumlah lot pesanan awal yang dijadikan acuan dimana pertambahan jumlah lot pesanan pada siklus berikutnya setara dengan persentase kerusakan barang $(p)$ yang diterima pada $Q$ $(p \times Q)$.

\subsection{Kenaikan Jumlah Lot Pesanan Pada Siklus Kedua $\left(\Delta Q_{1}\right)$}

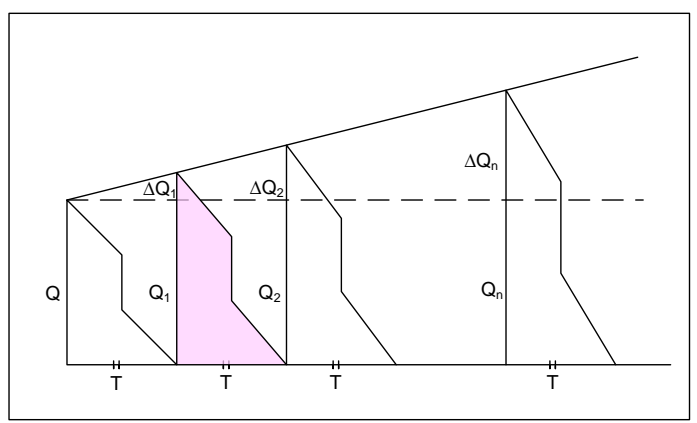

Gambar 4. Jumlah pesanan pada siklus kedua $\left(Q_{1}\right)$

Jika jumlah lot pesanan yang diterima pada awal siklus adalah $y=Q$ dengan persentase kerusakan barang $p$, dengan asumsi bahwa lot pesanan pada siklus berikutnya adalah sejumlah $p x Q$, maka kenaikan jumlah lot pesanan yang diterima pada siklus ke-2 $(\Delta Q 1)$ adalah:

$$
\Delta Q 1=p \times Q
$$

\subsection{Kenaikan Jumlah Lot Pesanan Pada Siklus Ketiga $\left(\Delta Q_{2}\right)$}

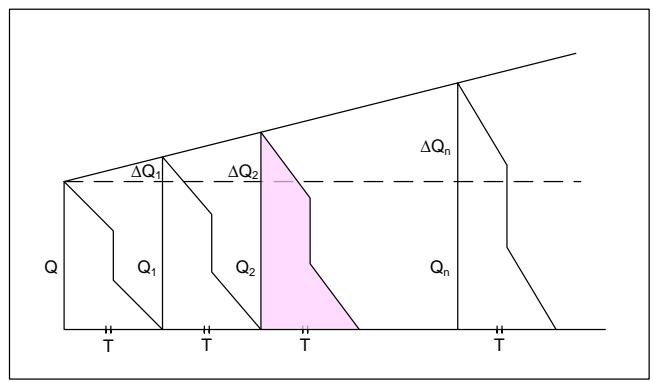

Gambar 4. Jumlah pesanan pada siklus kedua $\left(Q_{2}\right)$

Dengan asumsi yang sama, maka dapat dihitung kenaikan jumlah lot pesanan pada siklus kedua $\left(\Delta Q_{2}\right)$, yaitu persentase barang rusak $(p)$ yang diterima pada siklus awal $(Q)$, yaitu sebagai berikut:

$\Delta Q_{2}=p \times Q_{1}$

karena $\Delta Q_{1}=p \times Q$, maka:

$$
\begin{aligned}
\Delta Q_{2} & =p\left(Q+\Delta Q_{1}\right) \\
& =p[Q+(p \times Q)] \\
& =p Q+p^{2} Q \\
\Delta Q_{2} & =Q\left(p+p^{2}\right)
\end{aligned}
$$

Agar semakin jelas, kenaikan jumlah lot yang diterima pada siklus ke-4 $\left(\Delta Q_{3}\right)$, dapat dihitung sebagai berikut:

$$
\begin{aligned}
\Delta Q_{3} & =p \times Q_{2} \\
& =p \times\left(Q+\Delta Q_{2}\right) \\
& =p \times\left[Q+\left\{Q\left(p+p^{2}\right)\right\}\right] \\
& =p Q+p Q\left(p+p^{2}\right) \\
& =p Q\left(p^{2} Q+p^{3} Q\right) \\
& =Q\left(p+p^{2}+p^{3}\right)
\end{aligned}
$$

\subsection{Kenaikan Jumlah Lot Pesanan Pada Siklus ke-n $\left(\Delta Q_{n}\right)$}




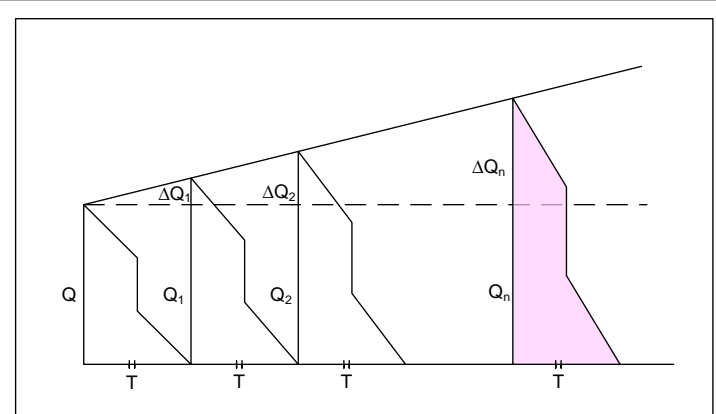

Gambar 5. Jumlah pesanan pada siklus kedua $\left(Q_{n}\right)$

Dengan cara yang sama, kenaikan jumlah lot pesanan yang diterima pada siklus ke- $n$ dapat dihitung.

$$
\Delta Q^{n}=Q\left(p+p^{2}+p^{3}+\ldots+p^{n}\right)
$$

Kenaikan jumlah lot pesanan pada model ini ternyata membentuk suatu deret geometri, dimana $S_{n}=a \frac{\left(1-r^{n}\right)}{1-r}$ dengan $0 \leq p \leq 1$, sehingga jumlah lot pesanan yang diterima pada siklus ke-n dapat dihitung sebagai berikut:

$$
\begin{aligned}
\Delta Q_{n} & =Q\left(p+p^{2}+p^{3}+\ldots+p^{n}\right) \\
\Delta Q_{n} & =Q\left[\frac{p\left(1-p^{n}\right)}{1-p}\right]
\end{aligned}
$$

maka

$$
\begin{aligned}
Q_{n} & =Q+Q\left[\frac{p\left(1-p^{n}\right)}{1-p}\right] \\
Q_{n} & =Q\left[1+\frac{\left.p-p^{n+1}\right)}{1-p}\right] \\
& =Q\left[\frac{(1-p)+\left(p-p^{n+1}\right)}{1-p}\right] \\
Q_{n} & =Q\left[\frac{1-p^{n+1}}{1-p}\right]
\end{aligned}
$$

Dengan demikian, pertambahan inventori pada siklus-siklus berikutnya dapat dihitung dengan persamaan:

$$
\begin{aligned}
\Delta Q_{n} & =Q \sum_{i=1}^{n+1} p^{i} \\
& \sum_{i=1}^{n+1} p^{i} \text { merupakan deret geometri dengan }
\end{aligned}
$$

barisan awal (a) sama dengan $p$, dan rasio $(r)=p, 0$ $<r<1$

Untuk kasus ini masalah dibatasi pada kasus untuk $\mathrm{n}+1$ (bukan tak hingga), sehingga persamaan (2) menjadi:

$$
\Delta Q_{n}=Q\left[\frac{p\left(1-p^{n+1}\right)}{1-p}\right]
$$

\subsection{Total Revenue (TR)}

Total revenue pada model ini adalah hasil penjualan produk berkualitas baik $(x)$ dikurangi dengan hasil penjualan produk cacat yang telah mengalami pemeriksaan sebelumnya $(v)$. Berdasarkan persamaan (3), maka total revenue dapat dihitung dengan menggunakan persamaan sebagai berikut:

$$
\begin{aligned}
& T R(Q)=x \cdot Q(1-p)+v Q p \\
& T R\left(Q_{1}\right)=x \cdot Q_{1}(1-p)+v Q_{l} p \\
& : \\
& : \\
& T R\left(Q_{n}\right)=x \cdot Q_{n}(1-p)+v Q_{n} p
\end{aligned}
$$

\subsection{Total Ongkos (TC)}

Ongkos yang harus ditanggung oleh pemilik inventori terdiri dari ongkos pengadaan, ongkos pemeriksaan, dan ongkos simpan. Pada model yang dikembangkan oleh Salameh dan Jaber, total ongkos yang harus ditanggung adalah total dari ongkos pengadaan, ongkos pemeriksaan, dan ongkos simpan inventori untuk satu siklus; perhitungannya adalah sebagai berikut:

$T C(y)=K+c y+d y+h \times\left[\frac{y(1-p) T}{2}+\frac{y^{2} p}{s}\right]$ 
Sedangkan total ongkos inventori yang dikembangkan pada model ini adalah total ongkos dari $\mathrm{n}$ siklus yang direncanakan, sesuai dengan pertambahan inventori $(Q)$ dan total siklus, yaitu:

$T C(Q)=a+c q+w Q+h\left[\frac{Q(1-p) T}{2}+\frac{Q^{2} p}{s}\right]$

$T C\left(Q_{1}\right)=\left(a+c q_{1}\right)+w Q_{1}+h\left[\frac{Q_{1}(1-p) T}{2}+\frac{Q_{1}^{2} p}{s}\right]$

$T C\left(Q_{n}\right)=\left(a+c q_{n}\right)+w Q_{n}+h\left[\frac{Q_{n}(1-p) T}{2}+\frac{Q_{n}^{2} p}{s}\right]$

\subsection{Total Keuntungan (TP)}

Total profit per siklus adalah total revenue per siklus dikurangi dengan total ongkos per siklus, sebagai berikut:

$$
\begin{aligned}
T P(Q)= & T R(Q)-T C(Q) \\
T P\left(Q_{n}\right)= & {\left[x \cdot Q_{n}(1-p)+v Q_{n} p\right]-\left(a+c q_{n}\right)+w Q_{n} } \\
& +h\left[\frac{Q_{n}(1-p) T}{2}+\frac{Q_{n}^{2} p}{s}\right]
\end{aligned}
$$

\subsection{Total Keuntungan per Unit (TPU)}

Dengan mereduplikasi model Salameh untuk persamaan (4) dan (5), maka total keuntungan $T P U(Q n)$ untuk setiap unit waktu per siklus adalah total revenue dikurangi total ongkos, yaitu sebagai berikut:

$$
\begin{aligned}
T P U(Q)= & D\left(s-v+\frac{h y}{x}\right)+D\left(v-\frac{h y}{x}-c-d-\frac{K}{Q}\right)\left(\frac{1}{1-p}\right) \\
& -\left(\frac{h y(1-p)}{2}\right)
\end{aligned}
$$

Untuk menghitung total profit per unit pada model ini adalah

$$
\begin{aligned}
\operatorname{TPU}\left(Q_{n}\right)= & \lambda\left(x-v-\frac{h Q_{n}}{s}\right)+\lambda\left(v-\frac{h Q_{n}}{s}-c-w-\frac{a}{Q_{n}}\right)\left(\frac{1}{1-p}\right) \\
& -\frac{h Q_{n}}{2}(1-p)
\end{aligned}
$$

Karena $p$ adalah variabel acak dengan fungsi kepadatan $f(p)$, maka nilai ekspektasi persamaan (7) adalah:

$$
\begin{aligned}
\operatorname{ETPU}\left(Q_{n}\right) & =\lambda\left(x-v-\frac{h Q_{n}}{s}\right)+\lambda\left(v-\frac{h Q_{n}}{s}-c-w-\frac{a}{Q_{n}}\right) E\left[\frac{1}{1-p}\right] \\
& -\frac{h Q_{n}}{2}(1-E[p])
\end{aligned}
$$

Untuk menentukan titik kritis yang memberikan keuntungan yang optimal, ETPU $(Q n)$ diturunkan terhadap $Q n$ dan dibuat sama dengan nol sebagai berikut:

$$
\begin{aligned}
\operatorname{ETPU}^{\prime}\left(Q_{n}\right)= & \frac{h \lambda}{s}-\frac{h \lambda}{s} E\left[\frac{1}{1-p}\right]+\frac{a \lambda}{Q_{n}^{2}} E\left[\frac{1}{1-p}\right] \\
& -\frac{h}{2}+\frac{h E[p]}{2}
\end{aligned}
$$

Dengan mensubstitusikan persamaan (4) ke persamaan (8) maka diperoleh:

$$
\begin{aligned}
E T P U^{\prime}\left(Q_{n}\right)= & \frac{h \lambda}{s}-\frac{h \lambda}{s} E\left[\frac{1}{1-p}\right] \\
& +\frac{a \lambda}{Q^{2} E\left[\frac{1-p^{n+1}}{1-p}\right]^{2}} E\left[\frac{1}{1-p}\right] \\
& -\frac{h}{2}+\frac{h E[p]}{2}=0 \\
0= & \frac{h \lambda}{s}-\frac{h \lambda}{s} E\left[\frac{1}{1-p}\right]+\frac{a \lambda}{Q^{2}} \times \frac{E[1-p]}{E\left[\left(1-p^{n+1}\right)^{2}\right]} \\
& -\frac{h}{2}+\frac{h E[p]}{2} n
\end{aligned}
$$

Maka

$$
Q^{*}=\sqrt{\frac{2 a \lambda E\left[\frac{1-p}{\left(1-p^{n+1}\right)^{2}}\right]}{h\left[1-E[p]-\frac{\lambda}{s}\left(1-E\left[\frac{1}{1-p}\right]\right)\right]}}
$$


Untuk menguji apakah $Q^{*}$ mengoptimalkan persamaan (7), maka turunan kedua, ETPU” (Qn), haruslah $0 \forall Q n \in \mathfrak{s}$ :

$\operatorname{ETPU}^{\prime \prime}(Q n)=\frac{-2 a \lambda E\left[\frac{1-p}{\left(1-p^{n+1}\right)^{2}}\right]}{Q^{3}} \leq 0, \forall \mathrm{Q} \in \aleph$

Jika nilai $\mathrm{p}=0$, maka persamaan (9) menjadi:

$$
\begin{aligned}
& Q^{*}=\sqrt{\frac{2 a \lambda E[1]}{h\left[1-E[0]-\frac{\lambda}{s}(1-E[1])\right]}} \\
& Q^{*}=\sqrt{\frac{2 a \lambda}{h}}
\end{aligned}
$$

\section{CONTOH NUMERIK}

Untuk mengilustrasikan manfaat model yang dikembangkan pada Bagian 3, berikut ini adalah situasi dimana kebutuhan inventori dipenuhi secara seketika dan tidak seluruh barang yang diterima berkualitas baik. Parameter yang diperlukan untuk menganalisis kasus inventori tersebut adalah sebagai berikut:

$$
\begin{aligned}
\lambda & =50.000 \text { unit per tahun } \\
\mathrm{a} & =100 \text { unit per siklus } \\
\mathrm{h} & =\$ 5 \text { per unit per tahun } \\
\mathrm{S} & =1 \text { unit per tahun } \\
\mathrm{w} & =\$ 0,5 \text { per unit } \\
\mathrm{c} & =\$ 25 \text { per unit } \\
\mathrm{x} & =\$ 50 \text { per unit } \\
\mathrm{v} & =\$ 20 \text { per unit } \\
\mathrm{n} & =\quad \text { Siklus ke-3 }
\end{aligned}
$$

Jika jumlah jam kerja per hari adalah 8 jam, dan 1 tahun $=365$ hari, maka laju pemeriksaan inventori tahunan, $s=1 \times 60 \times 8 \times 365=175.200$ unit per tahun. Dengan asumsi bahwa persentase barang yang rusak adalah variabel acak yang berdistribusi seragam dengan fungsi kepadatan sebagai berikut:

$$
f(p)=\left\{\begin{array}{l}
25, \quad 0 \leq p \leq 0,04 \\
0, \text { lainnya }
\end{array}\right.
$$

Untuk menghindari kekurangan inventori, maka persamaan (3) harus memenuhi persyaratan sebagai berikut:

$$
\begin{aligned}
& p \leq 1-\frac{\lambda Q}{s} \Rightarrow 1-5000 \times \frac{1}{175.200} \\
& p \leq 0,715
\end{aligned}
$$

Dari persamaan (11), diperoleh $0 \leq \mathrm{p} \leq 0,04$ dengan

$$
\begin{aligned}
& E[p]=\int_{a}^{b} p \cdot f(p) d p=\int_{0}^{0,04} 25 p d p=0,02 \\
& E\left[\frac{1}{1-p}\right]=\int_{a}^{b}\left(\frac{1}{1-p}\right) f(p) d p=25 \int_{0}^{0,04}\left(\frac{1}{1-p}\right) d p=1,02055 \\
& E\left[\frac{1-p}{\left(1-p^{4}\right)^{2}}\right]=\int_{a}^{b}\left(\frac{1-p}{\left(1-p^{4}\right)^{2}}\right) f(p) d p=25 \int_{0}^{0,04}\left(\frac{1-p}{\left(1-p^{4}\right)^{2}}\right) d p=0.98
\end{aligned}
$$

Maka nilai optimum $Q^{*}$ yang memaksimumkan persamaan (8) berasal dari persamaan (8):

$$
\begin{aligned}
& Q^{*}=\sqrt{\frac{2 \times 100 \times 50.000 \times 0,98}{5\left[(1-0,02)-50.000\left(\frac{1-1,02055}{175.200}\right)\right]}} \\
& Q^{*}=1.414 \text { unit }
\end{aligned}
$$

Dengan mengestimasi persentase kerusakan $(p)$ persamaan (4), sesuai dengan syarat persamaan (10):

$$
\begin{aligned}
& Q_{n_{\text {estimasi }}}=Q E\left[\frac{1-p^{n+1}}{1-p}\right] \\
& E\left[\frac{1-p^{4}}{(1-p)}\right]=\int_{a}^{b}\left(\frac{1-p^{4}}{(1-p)}\right) f(p) d p=25 \int_{0}^{0,04}\left(\frac{1-p^{4}}{(1-p)}\right) d p=1,02055
\end{aligned}
$$

Kemudian mensubstitusikan nilai $Q^{*}$ pada persamaan (12), diperoleh $\mathrm{Qn}^{*}=1,02055$ x $1.414=1.444$ unit.

Selanjutnya, nilai $Q n *$ yang diperoleh disubstitusikan pada persamaan (8). 


$$
\begin{aligned}
\operatorname{ETPU}\left(Q_{n}\right)= & \lambda\left(x-v-\frac{h Q_{n}}{s}\right)+\lambda\left(v-\frac{h Q_{n}}{s}-c-w-\frac{a}{Q_{n}}\right) \times \\
& E\left[\frac{1}{1-p}\right]-\frac{h Q_{n}}{2}(1-E[p]) \\
= & 50.000\left(50-20-\frac{5(1.444)}{175.200}\right)+ \\
& 50.000\left(20-\frac{5(1.444)}{175.200}-25-0,5-\frac{100}{1.444}\right) \times \\
& 1,02055-\frac{5(1.444)}{2} \cdot(1-0,02) \\
= & 1.497 .940+(-286.227)-3.538 \\
= & 1.208 .175 / \text { year }
\end{aligned}
$$

\section{KESIMPULAN}

Makalah ini membahas model EOQ dengan permintaan bersifat linier yang memperhitungkan keberadaan produk-produk cacat.

Hasil numerik menunjukkan bahwa walaupun permintaan meningkat selama siklus tertentu, keuntungan yang diperoleh lebih rendah daripada yang ditunjukkan oleh model Salameh dan Jaber.

\section{REFERENSI}

Yanasse HH. (1990). EOQ Systems: The Case of an Increase in Purchase Cost. Journal of Operational Research Society; 41 (7): 633 637

Salameh \& Jaber. (2000). Economic Production Quantity Model for Items with Imperfect Quality. International Journal of Production Economics; 64. pp. $59-64$.

Wen-Kai \& Hong-Fwu. (2009). EOQ Model for Imperfective Items Under a One-time-only Discount. Omega The International Journal of Management Science, 37. pp. 1018-1026.

Tersine. (1988). Principles of Inventory and

Materials Management, $3^{\text {rd }}$ Edition. Elsevier Science Publishing Co. Inc., New York. 